\title{
As estratégias de aprendizagem como forma de promover a interdisciplinaridade e 0 aprender a aprender.
}

\author{
Elis Regina da Costa ${ }^{1}$; Lucas nome do autor ${ }^{2}$
}

\section{Resumo}

Dentre os fatores que afetam o processo de aprendizagem dos alunos estão as estratégias de aprendizagem que podem ser entendidas como métodos ou procedimentos utilizados pelo aluno para aprender, armazenar e utilizar o conhecimento. A presente investigação, de natureza descritiva e correlacional possuía como propósito investigar e comparar o uso de estratégias de aprendizagem por parte de alunos universitários do primeiro e último ano dos cursos de História e Psicologia, de ambos os sexos, em situações de sala de aula, em situações de estudo e na realização de tarefas escolares (em casa). O instrumento utilizado para a coleta de dados foi a "Escala de Avaliação de Estratégias de Aprendizagem" de autoria de Santos e Boruchovitch (2008), que consta de 49 itens fechados, em forma de escala Likert, sendo 19 relativos às estratégias de aprendizagem Cognitivas 23 referentes a estratégias de aprendizagem metacognitivas Positivas e 9 do tipo Metacognitiva Negativas (ou disfuncionais). Os dados demonstraram que, os estudantes dos cursos de Psicologia e História relataram usar estratégias de aprendizagem semelhantes em suas atividades de estudo e aprendizagem. No curso de Psicologia, as alunos do sexo feminino em comparação ao masculino relataram utilizar estratégias metacognitivas mais frequentemente nas atividades de estudo. Ao se analisar as estratégias metacognitivas disfuncionais e o gênero constatou-se que os alunos do primeiro período em relação ao último relataram menos comportamentos inadequados. Em relação à formação focada na proposta interdisciplinar, reconhece-se cada vez mais a necessidade de processos educacionais formativos que promovam

1

Doutora em Educação pela Unicamp, Docente da Unidade Aacdêmica Especial - Educação da Regional Catalão. Este trabalho foi baseado no projeto de pesquisa investigando as estratégias de aprendizagem de universitários da cidade de Jataí - GO: enfocando os curso de formação de professores. pesquisa foi financiada pela CAPES, elisufg@gmail.com.

2

Mesmas informações Lucas...bolsa pibic.... 
a crítica construtiva, a responsabilidade social assim como, a autonomia intelectual dos futuros profissionais. As estratégias de aprendizagem podem se constituir em um instrumento para desenvolver e potencializar esse processo de construção critica por meio do aprender a aprender.

Palavras Chave: estratégias de aprendizagem; formação de professores; interdisciplinaridade. 